\title{
Cleaner air for China
}

\author{
China's rigorous air-pollution control has greatly reduced the levels of fine particles in the atmosphere. Further \\ progress for air quality more broadly will rely on fully accounting for complex chemical reactions between pollutants.
}

\section{T} his year the United Nation's World Environment Day on 5 June 2019 shone a spotlight on air pollution. The official celebrations took place in China, a country whose choking air has frequently made international headlines. This year, the outlook is more optimistic. China's Ministry of Ecology and Environment (https://go.nature.com/2xaWNEI) reported a significant decline in the annual-mean level of fine particulates, known as $\mathrm{PM}_{2.5}$ : concentrations fell by $42 \%$ between 2013 and 2018 across 74 large cities in China. A roundtable discussion between scientists specializing in atmospheric chemistry, economy and environmental health was arranged by Nature Geoscience in Beijing on 6 June 2019. It concluded that in order to make further progress, the focus of environmental controls in China must be broadened to other pollutants and their precursors.

The rapid improvement in air quality in China has been driven by strong political commitment. After a series of extreme pollution events in 2013, the central government made a firm promise to fight air pollution. Over the past six years, this commitment has been translated into concrete measures, such as enhancing endof-pipe control and optimizing industrial structure, and the success is now evident. However, it will be increasingly difficult for China to maintain the same rate of air-quality improvement. And reducing concentrations of air pollutants to the levels recommended by the World Health Organization is the next - and more difficult - challenge for China.

China's air pollution is different from the mix found in Europe and North America: it is characterized by enormous levels of anthropogenic emissions and highly complex chemical reactions in the atmosphere. The heavy burden of pollution in China is deeply rooted in the country's emission-intensive industries and coal-dominated energy structure. And extraordinarily rapid economic development, with a concurrent boom in industry and urbanization, has led to a coincidence of pollution sources that have been characteristic of different phases of socioeconomic development in Europe and North America. As a result, anthropogenic sources of emissions are complex and the amounts of pollutants emitted, such as sulfur dioxide $\left(\mathrm{SO}_{2}\right)$, nitrogen oxides $\left(\mathrm{NO}_{x}\right)$ and carbon monoxide, are many times higher than those currently emitted in Europe and North America. Once released, those pollutants can be involved in complex chains of chemical reactions in the atmosphere that make it difficult to control secondary pollutants.

Nevertheless, $\mathrm{PM}_{2.5}$ pollution in China has been successfully reduced, thanks to a comprehensive emission control. Since 2012, a series of stricter emission standards have replaced the old ones in order to target pollutants from power plants, emissionintensive industries, such as iron and steel, and vehicles. Meanwhile, the government also actively cracked down on high-emission and technologically outdated factories, and promoted shifts from coal to gas in residential heating. These various measures led to cuts in $\mathrm{SO}_{2}, \mathrm{NO}_{x}$ and black carbon by $59 \%, 21 \%$ and $28 \%$, respectively, during

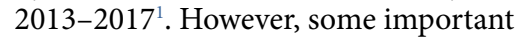
precursors of secondary aerosols continue to increase, such as non-methane volatile organic compounds and ammonia ${ }^{1}$.

In the next phase of $\mathrm{PM}_{2.5}$ control, instead of targeting $\mathrm{PM}_{2.5}$ as a single pollutant, a species-targeted control policy is needed. $\mathrm{PM}_{2.5}$ is a mix of chemicals composed of primary pollutants, such as black carbon, and secondary pollutants, such as sulfate, nitrate, ammonium and secondary organic aerosols. A large proportion of $\mathrm{PM}_{2.5}$ in China is composed of secondary compounds, especially during extreme pollution events. These compounds can constitute up to $70 \%$ of the concentration in metropolitan areas ${ }^{2}$. Despite the decline in $\mathrm{PM}_{2.5}$ concentration, the share of secondary compounds is continually increasing ${ }^{3}$. Nitrate and secondary organic aerosols may not reduce by the same magnitude as the bulk $\mathrm{PM}_{2.5}$ concentration. Therefore, effective controls on non-methane volatile organic compounds, ammonia and $\mathrm{NO}_{x}$ emissions would probably be of great importance for further $\mathrm{PM}_{2.5}$ control ${ }^{3}$, particularly for non-methane volatile organic compounds and ammonia, which are currently far more poorly constrained.

While $\mathrm{PM}_{2.5}$ levels have been successfully reduced in Chinese cities, years of $\mathrm{PM}_{2.5}$ control have had unintended effects on the surface ozone, an irritant of the respiratory system. The changes in anthropogenic emissions that significantly improved air quality in terms of $\mathrm{PM}_{2.5}$ levels, led to a change in the ratio of chemicals in the air and resulted in an intensification of ozone pollution across many important regions in China between 2013 and $2017^{4}$. In order to get ozone levels under control, sophisticated regulations of emission reduction based on local atmospheric chemistry are needed; otherwise, reducing its precursors may even cause an increase in summer surface ozone concentrations ${ }^{5}$. Moreover, trade-offs may occur in the controls of ozone and $\mathrm{PM}_{2.5}$, which require a deep understanding of the chemical reaction between pollutants to allow for a smart design of regulations that reduce both pollutants ${ }^{6}$. Achieving a coordinated control of $\mathrm{PM}_{2.5}$ and ozone will be one of the biggest challenges for the next phase of China's air-cleaning campaign.

Not all regulations have been as successful as the measures for abating $\mathrm{PM}_{2.5}$ pollution. For example, the emission of methane, a greenhouse gas that is two orders of magnitude more potent than $\mathrm{CO}_{2}$, rose by $1.1 \mathrm{Tg}$ annually in China from 2010 to $2015^{7}$. The increase was largely caused by emissions from coal mining, even though a set of regulations for constraining coal mining-derived methane emissions had started to come into force as early as $2010^{7}$.

The experience gained in China can help inform efforts to control air pollution in other countries that are undergoing fast economic development. For example, in India, which is already one of the most polluted countries, air quality is deteriorating rapidly. It is hoped that improvements can be spread swiftly. An around-the-world transfer of effective measures for cleaner air could benefit a vast amount of people.

Published online: 27 June 2019 https://doi.org/10.1038/s41561-019-0406-7

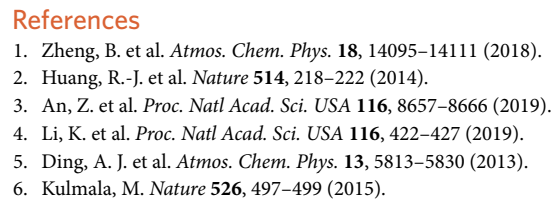

